To be submitted as a Research Full-length Paper to Schizophrenia Research

\title{
Metabotropic Glutamate Receptor 5 Neuroimaging in Schizophrenia
}

Funda Akkus ${ }^{\mathrm{a}}$, Valerie Treyer ${ }^{\mathrm{b}}$, Simon M. Ametamey ${ }^{\mathrm{c}}$, Anass Johayem ${ }^{\mathrm{b}}$, Alfred Buck ${ }^{\mathrm{b}}$, Gregor Hasler ${ }^{\mathrm{a}^{*}}$

${ }^{1}$ Psychiatric University Hospital, University of Bern, 3000 Bern 60, Switzerland

${ }^{2}$ PET Center, Division of Nuclear Medicine, University Hospital, 8091 Zurich, Switzerland

${ }^{3}$ Center for Radiopharmaceutical Science of ETH, PSI, and USZ, Department of Chemistry and Applied Biosciences of ETH, 8093 Zurich, Switzerland

${ }^{\S}$ These authors contributed equally to this work.

Running title: Metabotropic Glutamate Receptor 5 in Schizophrenia

*Corresponding author: Gregor Hasler, M.D.

University Hospital of Psychiatry, University of Bern

Bolligenstrasse 111, 3000 Bern, Switzerland.

Tel.: +4131 930-9543; fax: +41319309921.

Email: gregor.hasler@puk.unibe.ch,g.hasler@bluewin.ch 


\begin{abstract}
The metabotropic glutamate receptor 5 (mGluR5) is a promising drug target for the treatment of schizophrenia. In this study, we compared mGluR5 distribution volume ration (DVR) in subjects with schizophrenia and healthy controls. Given our previous findings, we matched samples for gender, age, and smoking status. Binding to mGluR5 was determined using positron emission tomography and $\left[{ }^{11} \mathrm{C}\right] \mathrm{ABP} 688$, which binds to an allosteric site with high selectivity. DVR in the 15 individuals with schizophrenia did not differ from that of the 15 controls. In both groups, smoking was associated with marked global reductions in mGluR5 availability (on average 23.8\%). In nonsmoking subjects with schizophrenia, there was a positive correlation between mGluR5 DVR in the medial orbitofrontal cortex and the use of antipsychotic drugs ( $r=0.9, p=0.019)$. Because antipsychotic drugs such as clozapine appeared to have indirect effects on mGluR5 signaling, our findings may be clinically relevant. They also provide promising leads for elucidating the high comorbidity between schizophrenia and tobacco addiction. Low mGluR5 DVR in smokers my represent a risk factor for schizophrenia. Alternatively, smoking may counteract the potential upregulation of mGluR5 by antipsychotic drugs.
\end{abstract}

Key Words: schizophrenia, glutamate, nicotine, mGluR5, positron emission tomography 


\section{Introduction}

Current pathogenic models of schizophrenia emphasize hypofunction of the $N$-methyl-Daspartate (NMDA) receptor (Iwata et al., 2015; Kantrowitz and Javitt, 2010). There is growing evidence from genetic and animal studies that the metabotropic glutamate receptors 5 (mGluR5) critically modulates the NMDA receptor (Matosin et al., 2015a). Both receptors colocalize and share the same scaffolding proteins and show strong functional associations. Consequently, mGluR5 has been proposed as an important target for the development of antipsychotic drugs (Goff, 2015). In addition, mGluR5 may be directly involved in abnormal glutamate signaling in schizophrenia. Genetic deletion of mGluR5 in mice has been shown to trigger a schizophrenia-like phenotype with decreased sensorimotor gating and short-term spatial memory deficits (Brody et al., 2004; Gray et al., 2009). In rats, treatment with specific negative allosteric modulators of mGluR5 leads to similar behavioral deficits, including impairments in sensory processing, working memory, and executive function (Vales et al., 2010; Zou et al., 2007). In humans, the allele frequency distribution of an intragenic microsatellite of the mGluR5 gene, GRM5, has been associated with schizophrenia (Devon et al., 2001). Several recent genome-wide association studies confirmed the involvement putative SNPs in GRM5 (Matosin et al., 2015b). In animal models, administration of cannabinoids during adolescence were shown to a reduction in hippocampal mGluR5, which was associated with learning deficits (Gleason et al., 2012). In contrast, postmortem studies have found only minimal changes in mGluR5 mRNA and mGluR5 protein in schizophrenia (Corti et al., 2011; Gupta et al., 2005; Matosin et al., 2013; Volk et al., 2010).

There is limited evidence for the involvement of mGluR5 in the effects of currently available antipsychotic drugs. In mGluR5 knockout mice, chronic administration of clozapine reversed sensorimotor gating deficits and abnormal locomotion (Gray et al., 2009). In rats, typical and atypical antipsychotics increased mGluR5 mRNA expression (Iasevoli et al., 2010), while 
other studies did not show changes in mGluR5 binding following treatment with antipsychotic drugs, in either animals or human postmortem tissue (Matosin and Newell, 2013). In previous studies, we have demonstrated that smoking is associated with a marked global reduction in mGluR5 DVR (Akkus et al., 2013; Akkus et al., 2015). This is a potentially relevant finding because $60 \%-90 \%$ of individuals with schizophrenia smoke (Chapman et al., 2009), and they usually smoke more heavily and experience more difficulty quitting smoking than do smokers without schizophrenia (Tidey et al., 2005; Wing et al., 2012).

This is the first study to assess mGluR5 DVR in subjects with schizophrenia and test for a hypothetical difference in DVR between patients and healthy controls. We applied positron emission tomography (PET) with the radiolabeled mGluR5 antagonist 3-(6-methyl-pyridin-2-

ylethynyl)-cyclohex-2-enone-O-11C-methyl-oxime ([ $\left.\left.{ }^{11} \mathrm{C}\right] \mathrm{ABP} 688\right)$ (Ametamey et al., 2007). This radiotracer binds to an allosteric site on mGluR5 with high selectivity. Given that age, gender, and smoking have been associated with mGluR5 DVR (Akkus et al., 2013; Akkus et al., 2015), we matched cases and controls for age, gender, and smoking. Based on preclinical and postmortem findings, we hypothesized that lower mGluR5 binding would be present in schizophrenia. Based on our previous findings in smokers, we also hypothesized that there would be marked global reductions in mGluR5 binding in smokers from both diagnostic groups.

\section{Methods}

\subsection{Participants}

All participants were inpatients or outpatients from the University Hospital of Psychiatry, Bern, and were screened using the following tools to assess potential inclusion into the 
schizophrenia group: an unstructured clinical interview conducted by a psychiatrist; a Structured Clinical Interview according to the Diagnostic and Statistical Manual of Mental Disorders, Fourth Edition Text Revision; the Positive and Negative Syndrome Scale (PANSS); the Bern Psychopathology Scale (BPS); the Beck Anxiety Inventory (BAI); and the Beck Depression Inventory (BDI).

Criteria for exclusion were: additional current psychiatric, medical, or neurological disorders; a history of substance dependence; pregnancy; and breastfeeding. A fast magnetic resonance imaging scan was performed on each subject and assessed by a radiologist to exclude any structural brain pathology. Doses of antipsychotic medications were transformed into chlorpromazine equivalents, and estimates of their respective affinity for receptors were graded according to radioligand binding assays in post-mortem normal human brain tissue (Richelson and Souder, 2000). Receptors of interest (shared receptors where information was available) included D2, 5-HT1A, 5HT2A, 5HT2C, alpha adrenergic 1a and 2a, muscarinic acetycholine receptor 1 , and the histamine receptor H1. Participants were fully informed regarding the study purpose and procedures, and provided written informed consent (approved by the local ethics committee; Kantonale Ethikkommission Zürich) before any study-related procedure was performed. Subjects were nicotine-abstinent for at least one hour before acquisition of the PET scan.

\subsection{Positron emission tomography}

As in previous studies, we applied a bolus/infusion protocol (Carson et al., 1993) previously evaluated for PET with [ ${ }^{11}$ C]ABP688 (Burger et al., 2010). Our method allowed for reliable measurement of the relative distribution volume (DVR), and reduced potential bias due to arterial blood sampling required for absolute quantification. Equilibrium between the tracer in tissue and blood is achieved 40 min after commencing the radio-ligand infusion (Burger et al., 
2010).We checked the dynamic uptake curve of each patient for suitability. Catheters were placed in the right antecubital vein for tracer injection prior to scanning. Subjects were scanned using $\left[{ }^{11} \mathrm{C}\right] \mathrm{ABP} 688$ and a whole-body PET (Discovery VCT; GE Healthcare, Milwaukee, WI) in three-dimensional mode with an axial field of view of $14.6 \mathrm{~cm}$ and an inplane resolution of $7.0 \mathrm{~mm}$. For attenuation correction, low-dose computed tomography was acquired before tracer injection. A total of $600-800 \mathrm{MBq}$ of $\left[{ }^{11} \mathrm{C}\right] \mathrm{ABP} 688$ in a 50-mL volume was administered using an infusion pump (half was given as a bolus over 2 min and the other half infused over the next $58 \mathrm{~min}$ ). Image acquisition and reconstruction were performed as described earlier (Akkus et al., 2014; Ametamey et al., 2006; Deschwanden et al., 2011; Treyer et al., 2007), using the cerebellum as the reference region. Normalization of the images to MNI space was performed using averaged early frames image that resembles perfusion images using PMOD Fusion tool (Version 3.5). Transformation matrices were then applied to late frame images. Consistently we our previous studies, twelve standard regions of interest (ROIs) were included: 3 cortical (frontal, parietal, and temporal), 2 within the cingulate gyrus (anterior and posterior), 3 in the prosencephalon (caudate, putamen, and thalamus), 3 within the limbic system (medial orbitofrontal cortex [mOFC], amygdala, and medial temporal lobe), and a general grey-matter region. Analyses were conducted using PMOD (Version 3.5, PMOD Technologies, Switzerland).

\subsection{Statistical analysis}

SPSS 22 was used for statistical analysis. Spearman's correlation analysis method was used for correlation assessments. To assess group effects we used repeated measures general linear models when including all regions within one analysis or Student's t-test for direct univariate comparisons and post-hoc tests. Furthermore, a general linear model was used to test for various factors with regards to effects in a region of interest. If required Bonferroni 
corrections were applied considering non hypothesis guided multiple tests and were clearly stated in the text.. All reported $p$ values are two-sided

\section{Results}

The clinical characteristics of the15 patients with schizophrenia and 15 age- and gendermatched healthy subjects are shown in Table 1 . All patients were stably medicated and their respective antipsychotic medications were transformed into chlorpromazine equivalents. All patients took atypical neuroleptics (risperidone, paliperidone, quetiapine, clozapine), except for one patient treated with flupentixol and two with an atypical combined with zuclopenthixol.

We assessed differences in clinical characteristics between groups and other potential confounding factors. Age did not differ across the groups $\left(t_{28}=0.172, p>0.86\right)$, and there was no significant age difference between male and female subjects in the total sample $\left(t_{28}=\right.$ $-0.126, p=0.9)$. The groups differed with respect to BDI $\left(t_{28}=5.365, p=0.000\right)$;

schizophrenia, $14.3 \pm 9.0$; healthy subjects, $1.7 \pm 1.7)$ and BAI scores $\left(t_{28}=2.648, p=0.013\right.$; schizophrenia, $7.4 \pm 4.6$; healthy subjects, $3.1 \pm 4.2$ ).

As in Figure 1, we observed no significant difference in the mGluR5 DVR between those with schizophrenia and healthy subjects. The repeated measures general linear model using the 12 regions as repeated variables and group as factor revealed no between-subjects effects $\left(F_{(28,1)}=0.11 ; p>0.9\right)$. Even with gender, age, BDI, and BAI as potential covariates added to the above general linear model, there were no significant differences between the two groups $\left(F_{(24,1)}=0.114 ; p=0.738\right)$. Age as a covariate produced a rather high F-value but remained insignificant $\left(F_{(24,1)}=4.24 ; p=0.051\right)$. Adding smoking status as a second factor to the model, 
we found a significant difference between smokers and nonsmokers $\left(F_{(22,1)}=185.632 ; p=\right.$ 0.000; 23.8\% difference in DVR over all regions) which did not show an interaction with the diagnostic group $\left(\mathrm{F}_{(22,1)}=0.320 ; p=0.578\right)$ in the same model. The covariate BDI became significant for between-subjects effects $\left(\mathrm{F}_{(22,1)}=8.019 ; p=0.01\right)$ in this analysis but did not correlate with mGluR5 values.

There was no correlation between the receptor systems for the prescribed neuroleptics and the mGluR5 DVR. There was a slightly significant correlation with chlorpromazine equivalents in some regions but this was not significant after Bonferroni correction. A partial correlation controlling for smoking status did not reveal any overall significance. The supplement includes more information on mGluR5 DVR and clinical variables, including treatment setting, extrapyramidal side effects, dose and duration of current antipsychotic medication (Figures S1-S6; Tables S1 and S2).

MGluR5 levels in the mOFC correlated with the medication dose in nonsmokers subgroup ( $r$ $=0.9, p=0.019$ ). Also correcting for the non-significant correlation within the smoking patient group this effect stays significant (corrected significance level $=0.025$ ). In Figure 2, we depict the distribution in this key region.

Focusing on the same region, we identified a significant effect by testing interactions between gender differences, smoking and clinical status: between group and gender interaction we see a significant effect $\left(F_{(22,1)}=8.706 ; p=0.007\right)$, and a non-significant trend in the triple interaction $\left(F_{(22,1)}=3.884 ; p=0.061\right.$; see Figure 3).

Neither education level nor current use of cannabis revealed a significant effect on the mGluR5 DVR (t-Test analysis). Within the schizophrenia group, the PANSS total score and subscales scores, BPS scores, BDI total score, BAI total score, age of onset, and illness duration did not correlate with mGluR5 DVR (for more details see supplementary material). 


\section{Discussion}

This is the first PET study to investigate mGluR5 DVR in individuals with schizophrenia and healthy controls. We did not find a difference in mGluR5 DVR between groups. In subjects with schizophrenia, we did not find associations between mGLuR5 DVR, symptom severity, or symptom dimensions. In both diagnostic groups, smoking was associated with a marked global reduction in mGluR5 DVR. In nonsmoking subjects with schizophrenia, we found a positive correlation between mGluR5 DVR in the mOFC and the use of mostly atypical antipsychotic drugs. In the same region, we found a trend for a triple interaction between group, gender, and smoking status. Most interesting was the interaction in nonsmokers between gender and the diagnostic group: schizophrenia was associated with higher mGluR5 DVR in female subjects, but with lower mGluR5 DVR in male subjects $(p<0.05)$. This result is preliminary due to the small sample size, but revealed potential new insights, which should be followed up in further studies focusing on gender and smoking in schizophrenia. The finding is consistent with reports on gender-specific risk factors for smoking in schizophrenia (Johnson et al., 2010), and interactions between estradiol and mGluR5 in the pathogenesis of addiction (Peterson et al., 2015).

Previously, associations have been found between schizophrenia and the mGluR5 gene, GRM5, and genes associated with mGluR5 such as those coding for Homer proteins, the postsynaptic density-95 gene, and the regulator of G protein signaling 4, RGS4 (Devon et al., 2001; Matosin and Newell, 2013; Ting et al., 2012). The postmortem literature on mGluR5 in schizophrenia is ambiguous. The mRNA for mGLuR5 was variously increased in a specific layer and region of the prefrontal cortex (Ohnuma et al., 1998), decreased in individuals with schizoaffective disorders (Matosin and Newell, 2013), and unchanged in other studies (Fatemi et al., 2013; Matosin et al., 2015a; Ohnuma et al., 2000; Richardson-Burns et al., 2000; Volk 
et al., 2010). Studies on mGluR5 protein expression in schizophrenia have identified increased (Matosin et al., 2015a), decreased (Fatemi et al., 2013), and normal protein levels (Corti et al., 2011; Fatemi et al., 2013; Gupta et al., 2005; Matosin et al., 2013). This disagreement may be due to differences between regions, schizophrenia subtypes, sample composition, antipsychotic use, smoking, sample size, and biochemical assays.

Our finding that mGluR5 DVR did not differ between groups is consistent with the majority of studies using postmortem tissue. This may be due to the fact that the postmortem studies are subject to the same confounding factors as our imaging study. For instance, most postmortem studies did not examine mGluR5 in a cell-type specific manner or accounting for masked alterations for instance due to fast-spiking (GABA)-ergic interneurons. The hypothesis that mGluR5 is decreased in schizoaffective disorder would be consistent with our finding of decreased mGluR5 DVR in depression (Deschwanden et al., 2011). However, we did not find any association between mGluR5, depressive symptoms, or the BPS affect subscale in schizophrenia subjects.

The strengths of our study include the matching of cases and controls for smoking status. In a previous study we found a marked global reduction in mGluR5 in smokers and recent exsmokers (average abstinence duration of 25 weeks) (Akkus et al., 2013). In a follow-up study we found normal mGluR5 DVR in long-term ex-smokers and a trend for a relationship between low mGluR5 DVR and the risk of relapse (Akkus et al., 2015). Together, these data suggest that the down-regulation of mGluR5 is a mechanism underlying nicotine dependence and the high risk of relapse in ex-smokers. It is not yet clear whether this effect is pathogenic or an unsuccessful compensatory mechanism. In this study, we found preliminary evidence for an interaction between smoking and gender, which is consistent with important genderspecific factors in the pathogenesis of schizophrenia. 
The majority of individuals with schizophrenia are smokers and have a smoking cessation rate of $10 \%-27 \%$, compared with $43 \%$ for subjects without psychiatric conditions (Wing et al., 2012). The vulnerability hypothesis proposes that common genetic and environmental factors explain the high comorbidity between schizophrenia and nicotine addiction (Chambers, 2009). Dysfunction of the glutamatergic system may be a final common pathway increasing the risk of both conditions (Kalivas, 2009). Given growing evidence that smoking prospectively predicts risk for schizophrenia (Kendler et al., 2015), one might speculate that the marked global reduction of mGluR5 DVR in smokers constitutes a neurobiological risk factor for this severe psychiatric condition. For example, because mGluR5 and NMDA receptors are structurally and functionally closely connected, reduced mGluR5 signaling may contribute to NMDA receptor hypofunction that is thought to be a common final pathway of various schizophrenia symptoms including sensory deficits, general cognitive deficits, and impaired learning and memory (Kantrowitz and Javitt, 2010).

The self-medication hypothesis posits that subjects with schizophrenia smoke to reduce symptoms, particularly negative and cognitive symptoms, and the side effects of antipsychotic drugs such as drug-induced Parkinsonism (Winterer, 2010). The positive correlation between mGluR5 and antipsychotic use that we found in nonsmokers seems to support the selfmedication hypothesis with regard to medication side effects. In haloperidol-treated patients with schizophrenia, the application of nicotine through transdermal patches reduced bradykinesia-rigidity (Yang et al., 2002). Because the majority of subjects included in our study used atypical antipsychotics, one might conclude that this nicotine effect is irrelevant. However, newer antipsychotics also produce extrapyramidal side effects, particularly when used in higher doses and as part of a combination treatment, although we could not show such a relationship in our sample. The association between smoking and low mGluR5 DVR might represent a mechanism underlying the improvement of extrapyramidal side effects through 
nicotine consumption given that the specific pharmacological blocking of mGluR5 has emerged as one of the most attractive non-dopaminergic-based strategies in the management of motor symptoms in Parkinson’s Disease (Vallano et al., 2013). Previously, we reported on a positive correlation between anxiety-related symptoms and mGluR5 DVR (Akkus et al., 2014). As a result, smoking in schizophrenia may also help to reduce some of the non-motor side effects of antipsychotics related to their effects on glutamate signaling. Our study was not large enough to address this possibility.

Previous studies on the effects of antipsychotics on mGluR5 binding have been inconsistent. In rats, both haloperidol and sertindole increased mGluR5 mRNA (Iasevoli et al., 2010). However, another rat study did not find changes in mGluR5 protein expression following treatment with olanzapine and haloperidol (Matosin and Newell, 2013). In postmortem studies, no clear association between antipsychotic use and mGluR5 binding has been identified so far (Matosin et al., 2015a; Matosin et al., 2013). These data have to be interpreted with caution since the quality of data from postmortem studies is often questionable.

In nonsmokers with schizophrenia, female subjects showed increased, and male subjects showed decreased mGluR5 DVR. An interesting study on prenatal chronic mild stress in rats demonstrated that stress-related changes in mGluR5 expression were sex-specific (Wang et al., 2015). Although the direction of change was opposite to our findings, both studies point to the potential importance of sex-specific factors in the development of chronic psychiatric conditions. The functional relationships between estrogen receptors and mGluR5 (GroveStrawser et al., 2010) may contribute to sex-specific glutamatergic dysfunction in schizophrenia.

Several methodological limitations merit comment. Firstly, we oversampled the control group for smokers. In reality, individuals with schizophrenia might have lower mGluR5 binding 
than nonpsychotic subjects because they smoke more frequently and more heavily (Wing et al., 2012), although many individuals with schizophrenia do not smoke and we did not find a correlation between the amount of nicotine consumption and mGluR5 DVR. Secondly, our samples were relatively small to demonstrate a negative finding. This is particularly important because there were important subgroups regarding mGluR5 DVR. However, the effect of smoking on mGluR5 is so strong and consistent across studies that an increase in sample size unlikely changed the results of this study. Thirdly, the cross-sectional design of this study without repeated assessments of mGluR5 DVR cannot investigate the potentially complex interplay between schizophrenia vulnerability, smoking, and antipsychotic use on mGluR5 DVR. The relatively long illness duration might have influenced the results due to compensatory regulatory effects and long term medication effects. Fourthly, we did not exclude cannabis users because cannabis consumption is very common in schizophrenia and exclusion would have led to a markedly non-representative sample. Because only one nonsmoker was cannabis user and smoking had a very strong influence on mGluR5 DVR, we were not able to do more refined analyses on cannabis use. It may well be that cannabis or 9THC does not directly act on dopamine firing but indirectly by altering glutamate neurotransmission, which may have confounded the results of this study. Fifthly, individuals with schizophrenia were treated with antipsychotic medication, which may be have been an important confounding factor. Our analyses on medication did not show associations between chlorpromazine equivalents and mGluR5 DVR, which may be due to the fact that these equivalents adjust dosages regarding dopaminergic effects but not the influence on the glutamatergic system. Finally, in order to avoid potentially painful arterial cannulation, we used a bolus-infusion technique, normalizing PET images to the cerebellar radioactivity concentration. The normalization itself is never perfect and small regions can be incorrectly normalized, especially as the functional region outline might not be identical to the anatomical position of a region. We based our reference tissue method on the assumption that 
mGluR5 levels are very low in the cerebellum compared with predefined ROIs in other brain areas (Elmenhorst et al., 2010). Various types of evidence support this assumption, including in vitro and in vivo studies on binding to ABP688 in the cerebellum (Ametamey et al., 2007; Elmenhorst et al., 2010), a study on cerebellar mGluR5 protein expression in postmortem tissue (Deschwanden et al., 2011), previous PET studies (Barret et al., 2010), and studies on cerebellar mRNA expression (Berthele et al., 1999; Daggett et al., 1995; Malherbe et al., 2002).

In conclusion, we showed that mGluR5 DVR in the brains of subjects with schizophrenia is not different from that of healthy controls. As in controls, smoking was associated with a marked global reduction in mGluR5 DVR. This may be of clinical importance since antipsychotic drugs such as clozapine appear to have indirect effects on mGluR5 signaling (Gray et al., 2009). This study provides promising leads for elucidating the high comorbidity between schizophrenia and tobacco addiction. One may speculate that downregulation of mGluR5 in smokers is a risk factor for schizophrenia. Alternatively, smoking may counteract the potential upregulation of mGluR5 by antipsychotic drugs to counteract medication side effects. Finally, this study has revealed important sex-specific variations in the glutamatergic dysfunction underlying schizophrenia. Future mGluR5 imaging studies should include younger patients with a shorter illness duration to reduce potentially confounding factors such as long-term medication and examine the role of mGluR5 in early stages of the illness. 


\section{References}

Akkus, F., Ametamey, S.M., Treyer, V., Burger, C., Johayem, A., Umbricht, D., Gomez Mancilla, B., Sovago, J., Buck, A., Hasler, G., 2013. Marked global reduction in mGluR5 receptor binding in smokers and ex-smokers determined by [11C]ABP688 positron emission tomography. Proc Natl Acad Sci U S A 110(2), 737-742.

Akkus, F., Terbeck, S., Ametamey, S.M., Rufer, M., Treyer, V., Burger, C., Johayem, A., Mancilla, B.G., Sovago, J., Buck, A., Hasler, G., 2014. Metabotropic glutamate receptor 5 binding in patients with obsessive-compulsive disorder. Int J Neuropsychopharmacol 17(12), 1915-1922.

Akkus, F., Treyer, V., Johayem, A., Ametamey, S.M., Mancilla, B.G., Sovago, J., Buck, A., Hasler, G., 2015. Association of Long-Term Nicotine Abstinence with Normal Metabotropic Glutamate Receptor5 Binding. Biol Psychiatry in press.

Ametamey, S.M., Kessler, L.J., Honer, M., Wyss, M.T., Buck, A., Hintermann, S., Auberson, Y.P., Gasparini, F., Schubiger, P.A., 2006. Radiosynthesis and preclinical evaluation of 11C-ABP688 as a probe for imaging the metabotropic glutamate receptor subtype 5. J Nucl Med 47(4), 698-705. Ametamey, S.M., Treyer, V., Streffer, J., Wyss, M.T., Schmidt, M., Blagoev, M., Hintermann, S., Auberson, Y., Gasparini, F., Fischer, U.C., Buck, A., 2007. Human PET studies of metabotropic glutamate receptor subtype 5 with 11C-ABP688. J Nucl Med 48(2), 247-252.

Barret, O., Tamagnan, G., Batis, J., Jennings, D., Zubal, G., Russell, D., Marek, K., Seibyl, J., 2010. Quantitation of glutamate mGluR5 receptor with 18F-FPEB PET in humans. J Nucl Med 51(Supplement 2), 215.

Berthele, A., Platzer, S., Laurie, D.J., Weis, S., Sommer, B., Zieglgansberger, W., Conrad, B., Tolle, T.R., 1999. Expression of metabotropic glutamate receptor subtype mRNA (mGluR1-8) in human cerebellum. Neuroreport 10(18), 3861-3867.

Brody, S.A., Dulawa, S.C., Conquet, F., Geyer, M.A., 2004. Assessment of a prepulse inhibition deficit in a mutant mouse lacking mGlu5 receptors. Mol Psychiatry 9(1), 35-41.

Burger, C., Deschwanden, A., Ametamey, S., Johayem, A., Mancosu, B., Wyss, M., Hasler, G., Buck, A., 2010. Evaluation of a bolus/infusion protocol for 11C-ABP688, a PET tracer for mGluR5. Nucl Med Biol 37(7), 845-851.

Carson, R.E., Channing, M.A., Blasberg, R.G., Dunn, B.B., Cohen, R.M., Rice, K.C., Herscovitch, P., 1993. Comparison of bolus and infusion methods for receptor quantitation: application to [18F]cyclofoxy and positron emission tomography. J Cereb Blood Flow Metab 13(1), 24-42. Chambers, R.A., 2009. A Nicotine Challenge to the Self-Medication Hypothesis in a Neurodevelopmental Animal Model of Schizophrenia. J Dual Diagn 5(2), 139-148.

Chapman, S., Ragg, M., McGeechan, K., 2009. Citation bias in reported smoking prevalence in people with schizophrenia. Aust N Z J Psychiatry 43(3), 277-282.

Corti, C., Xuereb, J.H., Crepaldi, L., Corsi, M., Michielin, F., Ferraguti, F., 2011. Altered levels of glutamatergic receptors and $\mathrm{Na}+\mathrm{K}+$ ATPase-alpha1 in the prefrontal cortex of subjects with schizophrenia. Schizophr Res 128(1-3), 7-14.

Daggett, L.P., Sacaan, A.I., Akong, M., Rao, S.P., Hess, S.D., Liaw, C., Urrutia, A., Jachec, C., Ellis, S.B., Dreessen, J., et al., 1995. Molecular and functional characterization of recombinant human metabotropic glutamate receptor subtype 5. Neuropharmacology 34(8), 871-886.

Deschwanden, A., Karolewicz, B., Feyissa, A.M., Treyer, V., Ametamey, S.M., Johayem, A., Burger, C., Auberson, Y.P., Sovago, J., Stockmeier, C.A., Buck, A., Hasler, G., 2011. Reduced Metabotropic Glutamate Receptor 5 Density in Major Depression Determined by [11C]ABP688 PET and Postmortem Study. Am J Psychiatry 168(7), 727-734.

Devon, R.S., Anderson, S., Teague, P.W., Muir, W.J., Murray, V., Pelosi, A.J., Blackwood, D.H., Porteous, D.J., 2001. The genomic organisation of the metabotropic glutamate receptor subtype 5 gene, and its association with schizophrenia. Mol Psychiatry 6(3), 311-314. 
Elmenhorst, D., Minuzzi, L., Aliaga, A., Rowley, J., Massarweh, G., Diksic, M., Bauer, A., Rosa-Neto, P., 2010. In vivo and in vitro validation of reference tissue models for the $m G l u R(5)$ ligand [(11)C]ABP688. J Cereb Blood Flow Metab 30(8), 1538-1549.

Fatemi, S.H., Folsom, T.D., Rooney, R.J., Thuras, P.D., 2013. mRNA and protein expression for novel GABAA receptors theta and rho2 are altered in schizophrenia and mood disorders; relevance to FMRP-mGluR5 signaling pathway. Translational psychiatry 3, e271.

Gleason, K.A., Birnbaum, S.G., Shukla, A., Ghose, S., 2012. Susceptibility of the adolescent brain to cannabinoids: long-term hippocampal effects and relevance to schizophrenia. Transl Psychiatry 2, e199.

Goff, D.C., 2015. Drug development in schizophrenia: are glutamatergic targets still worth aiming at? Curr Opin Psychiatry 28(3), 207-215.

Gray, L., van den Buuse, M., Scarr, E., Dean, B., Hannan, A.J., 2009. Clozapine reverses schizophreniarelated behaviours in the metabotropic glutamate receptor 5 knockout mouse: association with $\mathrm{N}$ methyl-D-aspartic acid receptor up-regulation. Int J Neuropsychopharmacol 12(1), 45-60.

Grove-Strawser, D., Boulware, M.I., Mermelstein, P.G., 2010. Membrane estrogen receptors activate the metabotropic glutamate receptors mGluR5 and mGluR3 to bidirectionally regulate CREB phosphorylation in female rat striatal neurons. Neuroscience 170(4), 1045-1055.

Gupta, D.S., McCullumsmith, R.E., Beneyto, M., Haroutunian, V., Davis, K.L., Meador-Woodruff, J.H., 2005. Metabotropic glutamate receptor protein expression in the prefrontal cortex and striatum in schizophrenia. Synapse 57(3), 123-131.

lasevoli, F., Tomasetti, C., Marmo, F., Bravi, D., Arnt, J., de Bartolomeis, A., 2010. Divergent acute and chronic modulation of glutamatergic postsynaptic density genes expression by the antipsychotics haloperidol and sertindole. Psychopharmacology (Berl) 212(3), 329-344.

Iwata, Y., Nakajima, S., Suzuki, T., Keefe, R.S., Plitman, E., Chung, J.K., Caravaggio, F., Mimura, M., Graff-Guerrero, A., Uchida, H., 2015. Effects of glutamate positive modulators on cognitive deficits in schizophrenia: a systematic review and meta-analysis of double-blind randomized controlled trials. Mol Psychiatry 20, 1151-1160.

Johnson, J.L., Ratner, P.A., Malchy, L.A., Okoli, C.T., Procyshyn, R.M., Bottorff, J.L., Groening, M., Schultz, A., Osborne, M., 2010. Gender-specific profiles of tobacco use among non-institutionalized people with serious mental illness. BMC Psychiatry 10, 101.

Kalivas, P.W., 2009. The glutamate homeostasis hypothesis of addiction. Nat Rev Neurosci 10(8), 561572.

Kantrowitz, J.T., Javitt, D.C., 2010. N-methyl-d-aspartate (NMDA) receptor dysfunction or dysregulation: the final common pathway on the road to schizophrenia? Brain Res Bull 83(3-4), 108121.

Kendler, K.S., Lonn, S.L., Sundquist, J., Sundquist, K., 2015. Smoking and Schizophrenia in Population Cohorts of Swedish Women and Men: A Prospective Co-Relative Control Study. Am J Psychiatry 172(11), 1092-1100.

Malherbe, P., Kew, J.N., Richards, J.G., Knoflach, F., Kratzeisen, C., Zenner, M.T., Faull, R.L., Kemp, J.A., Mutel, V., 2002. Identification and characterization of a novel splice variant of the metabotropic glutamate receptor 5 gene in human hippocampus and cerebellum. Brain Res Mol Brain Res 109(1-2), 168-178.

Matosin, N., Fernandez-Enright, F., Fung, S.J., Lum, J.S., Engel, M., Andrews, J.L., Huang, X.F., Weickert, C.S., Newell, K.A., 2015a. Alterations of mGluR5 and its endogenous regulators Norbin, Tamalin and Preso1 in schizophrenia: towards a model of mGluR5 dysregulation. Acta Neuropathol 130(1), 119-129.

Matosin, N., Fernandez-Enright, F., Lum, J.S., Newell, K.A., 2015b. Shifting towards a model of mGluR5 dysregulation in schizophrenia: Consequences for future schizophrenia treatment. Neuropharmacology.

Matosin, N., Frank, E., Deng, C., Huang, X.F., Newell, K.A., 2013. Metabotropic glutamate receptor 5 binding and protein expression in schizophrenia and following antipsychotic drug treatment.

Schizophr Res 146(1-3), 170-176. 
Matosin, N., Newell, K.A., 2013. Metabotropic glutamate receptor 5 in the pathology and treatment of schizophrenia. Neurosci Biobehav Rev 37(3), 256-268.

Ohnuma, T., Augood, S.J., Arai, H., McKenna, P.J., Emson, P.C., 1998. Expression of the human excitatory amino acid transporter 2 and metabotropic glutamate receptors 3 and 5 in the prefrontal cortex from normal individuals and patients with schizophrenia. Brain Res Mol Brain Res 56(1-2), 207217.

Ohnuma, T., Tessler, S., Arai, H., Faull, R.L., McKenna, P.J., Emson, P.C., 2000. Gene expression of metabotropic glutamate receptor 5 and excitatory amino acid transporter 2 in the schizophrenic hippocampus. Brain Res Mol Brain Res 85(1-2), 24-31.

Peterson, B.M., Mermelstein, P.G., Meisel, R.L., 2015. Estradiol mediates dendritic spine plasticity in the nucleus accumbens core through activation of mGluR5. Brain Struct Funct 220(4), 2415-2422. Richardson-Burns, S.M., Haroutunian, V., Davis, K.L., Watson, S.J., Meador-Woodruff, J.H., 2000. Metabotropic glutamate receptor mRNA expression in the schizophrenic thalamus. Biol Psychiatry 47(1), 22-28.

Richelson, E., Souder, T., 2000. Binding of antipsychotic drugs to human brain receptors focus on newer generation compounds. Life Sci 68(1), 29-39.

Tidey, J.W., Rohsenow, D.J., Kaplan, G.B., Swift, R.M., 2005. Cigarette smoking topography in smokers with schizophrenia and matched non-psychiatric controls. Drug Alcohol Depend 80(2), 259-265. Ting, J.T., Peca, J., Feng, G., 2012. Functional consequences of mutations in postsynaptic scaffolding proteins and relevance to psychiatric disorders. Annu Rev Neurosci 35, 49-71.

Treyer, V., Streffer, J., Wyss, M.T., Bettio, A., Ametamey, S.M., Fischer, U., Schmidt, M., Gasparini, F., Hock, C., Buck, A., 2007. Evaluation of the metabotropic glutamate receptor subtype 5 using PET and 11C-ABP688: assessment of methods. J Nucl Med 48(7), 1207-1215.

Vales, K., Svoboda, J., Benkovicova, K., Bubenikova-Valesova, V., Stuchlik, A., 2010. The difference in effect of $\mathrm{mGlu2} / 3$ and $\mathrm{mGlu} 5$ receptor agonists on cognitive impairment induced by MK-801. Eur J Pharmacol 639(1-3), 91-98.

Vallano, A., Fernandez-Duenas, V., Garcia-Negredo, G., Quijada, M.A., Simon, C.P., Cuffi, M.L., Carbonell, L., Sanchez, S., Arnau, J.M., Ciruela, F., 2013. Targeting striatal metabotropic glutamate receptor type 5 in Parkinson's disease: bridging molecular studies and clinical trials. CNS Neurol Disord Drug Targets 12(8), 1128-1142.

Volk, D.W., Eggan, S.M., Lewis, D.A., 2010. Alterations in metabotropic glutamate receptor 1alpha and regulator of $\mathrm{G}$ protein signaling 4 in the prefrontal cortex in schizophrenia. Am J Psychiatry 167(12), 1489-1498.

Wang, Y., Ma, Y., Hu, J., Cheng, W., Jiang, H., Zhang, X., Li, M., Ren, J., Li, X., 2015. Prenatal chronic mild stress induces depression-like behavior and sex-specific changes in regional glutamate receptor expression patterns in adult rats. Neuroscience 301, 363-374.

Wing, V.C., Wass, C.E., Soh, D.W., George, T.P., 2012. A review of neurobiological vulnerability factors and treatment implications for comorbid tobacco dependence in schizophrenia. Ann N Y Acad Sci $1248,89-106$.

Winterer, G., 2010. Why do patients with schizophrenia smoke? Curr Opin Psychiatry 23(2), 112-119. Yang, Y.K., Nelson, L., Kamaraju, L., Wilson, W., McEvoy, J.P., 2002. Nicotine decreases bradykinesiarigidity in haloperidol-treated patients with schizophrenia. Neuropsychopharmacology 27(4), 684686.

Zou, D., Huang, J., Wu, X., Li, L., 2007. Metabotropic glutamate subtype 5 receptors modulate fearconditioning induced enhancement of prepulse inhibition in rats. Neuropharmacology 52(2), 476486. 


\section{Figure legends}

Figure 1. The distribution of all DVRs over all regions in both groups and their smoking status. Smoking status revealed strong differences, while the overlap between clinical groups was high.

Figure 2. The figure shows the effect of medication dose (converted in to chlorpromazine equivalents) on mGluR5 levels in the mOFC region of nonsmokers. All patients were medicated, and the medication level of zero refers to mGluR5 reference values for the control group. There was no correlation between medication equivalent levels and mGluR5 DVR in smokers. 
Table 1. Clinical characteristics of study groups

\begin{tabular}{|c|c|c|c|c|}
\hline Clinical characteristic & $\begin{array}{l}\text { Patients with } \\
\text { schizophrenia } \\
(n=15)\end{array}$ & & $\begin{array}{l}\text { Control } \\
\text { group } \\
(n=15)\end{array}$ & \\
\hline Gender (f/m) & $6 / 9$ & & $6 / 9$ & \\
\hline Smoker, $\boldsymbol{n}$ (f/m) & $9(3 / 6)$ & & $9(5 / 4)$ & \\
\hline Cigarette consumption (d) & $25.8(7.6)$ & & $18.9(4.3)$ & \\
\hline Years of consumption & $17.9(10.9)$ & & $15.4(7.9)$ & \\
\hline Age (years) & $38.2(10.7)$ & & $37.5(10.6)$ & \\
\hline Onset of illness (age in years) & $22.6(7.0)$ & & -- & \\
\hline Duration of illness (years) & $15.6(11.6)$ & & -- & \\
\hline $\begin{array}{l}\text { Medication (average dose mg/ } \\
\text { n number of patients) }\end{array}$ & $\begin{array}{l}\text { Clozapin(470/4) } \\
\text { Quetiapine(410/5) } \\
\text { Paliperidon(8/2) } \\
\text { Aripiprazol(10/2) } \\
\text { Risperidon(2/1) }\end{array}$ & & -- & \\
\hline Cannabis users & 5 & & 0 & \\
\hline \multicolumn{5}{|l|}{ Highest educational qualification: } \\
\hline High school uncompleted & 5 & & - & \\
\hline High school, completed & 14 & & 13 & \\
\hline College, completed & 1 & & - & \\
\hline Academic completed & - & & 2 & \\
\hline Subgroups & $\begin{array}{l}\text { Nonsmoker } \\
(n=6)\end{array}$ & $\begin{array}{l}\text { Smoker } \\
(n=9)\end{array}$ & $\begin{array}{l}\text { Nonsmoker } \\
(n=6)\end{array}$ & $\begin{array}{l}\text { Smoker } \\
(n=9)\end{array}$ \\
\hline Beck Anxiety Inventory score & 8.8 & 6.4 & 1 & 4.6 \\
\hline Beck Depression Inventory score & 12.2 & 15.8 & 1.3 & 1.9 \\
\hline PANSS Positive & $14.9(4.1)$ & $13.2(2.4)$ & -- & -- \\
\hline PANSS Negative & $17.7(8.1)$ & $20.8(9.1)$ & -- & -- \\
\hline
\end{tabular}


PANSS General

PANSS Total score
$27.6(11.9)$

$62.7(20.1)$
$35.0(8.3)$

$69(18.5)$

The data are displayed as means (SD), unless indicated otherwise.

$n$ refers to the number of participants within this category. 